\title{
Expression of transcription factor zinc-binding protein-89 (ZBP-89) is inhibited by inflammatory cytokines
}

This article was published in the following Dove Press journal:

Pathology and Laboratory Medicine International

20 August 2009

Number of times this article has been viewed

\author{
Ruth C Borghaei \\ Mariah Chambers \\ Department of Biochemistry \\ and Molecular Biology, Philadelphia \\ College of Osteopathic Medicine, \\ 4170 City Avenue, Philadelphia, \\ PA I9131, USA
}

\begin{abstract}
Zinc-binding protein-89 (ZBP-89; ZNF148, BERF-1, BFCOL-1) is a zinc-finger transcription factor of the Kruppel family. It has been shown to regulate the expression of a number of genes, acting as either an activator or repressor of gene expression, depending on the context. It is over-expressed in several cancers, but has been shown to be involved in apoptosis and to have a negative influence on cell growth in part by interactions with p53. Previously, ZBP-89 was shown to activate transcription of the matrix metalloproteinase-3 (MMP-3) gene by binding to a polymorphic promoter element in competition with nuclear factor $\kappa \mathrm{B}(\mathrm{NF}-\kappa \mathrm{B})$. NF- $\kappa \mathrm{B}$ is known to be a key regulator of the inflammatory response, but relatively little is known about regulation of ZBP-89. In order to ascertain whether ZBP-89 is regulated during inflammation, we designed experiments to determine whether and to what extent ZBP-89 levels are affected by inflammatory cytokines. Here we show that ZBP-89 mRNA and protein expression are significantly inhibited in human fibroblasts by the inflammatory cytokine interleukin-1 $\beta$. Since any change in the levels of ZBP-89 would presumably impact the regulation of MMP-3 and other ZBP-89 target genes, these results provide important insight into mechanisms involved in fine-tuning the immune response.
\end{abstract}

Keywords: ZBP-89, ZNF148, BERF-1, IL-1, TNF, fibroblasts

\section{Introduction}

Zinc-binding protein-89 (ZBP-89; ZNF148, BERF-1, BFCOL-1) is a ubiquitously expressed zinc-finger transcription factor of the Krüppel family. It has been shown to regulate the expression of a number of genes, acting as either an activator ${ }^{1-4}$ or repressor $^{5-10}$ of transcription, depending on the context. When ZBP-89 is a repressor of gene expression, it often accomplishes this by competing for an overlapping binding site with another transcription factor, usually $\mathrm{Sp} 1,5,7,11$ although the protein does also have a repression domain. ${ }^{8}$

The case of human matrix metalloproteinase 3 (MMP-3) is somewhat different, however, in that ZBP-89 has been shown to activate transcription in competition with NF- $\kappa \mathrm{B}$ for binding to a polymorphic $5 \mathrm{~T} / 6 \mathrm{~T}$ site in the promoter. ${ }^{4,12}$ This site was originally identified as a repressor element, with the $6 \mathrm{~T}$ version being a more effective repressor than the $5 \mathrm{~T}$ in transiently transfected fibroblasts. ${ }^{13}$ In COS- 1 cells, over-expressed ZBP-89 activated the 5T promoter more efficiently than the 6T, while $\mathrm{NF}-\kappa \mathrm{B}$ repressed both. ${ }^{12}$ This polymorphism is functionally significant in that it has been shown both to influence levels of MMP-3 in tissues ${ }^{14,15}$ and to be associated with increased risk or severity of several disease states. ${ }^{16-19}$ For example, individuals homozygous for the 6T site have been shown to express less MMP-3 protein in aortic

submit your manuscript | www.dovepress.com 
wall and dermal tissues and to have more rapid progression of atherosclerosis, ${ }^{14,15,18,19}$ while individuals homozygous for the $5 \mathrm{~T}$ site express more protein in tissues and are at increased risk for myocardial infarctions and aneurysms. ${ }^{16,17,20}$

Since the role of the polymorphism in determining the levels of MMP-3 protein expression likely depends on the relative concentrations of $\mathrm{NF}-\kappa \mathrm{B}$ and ZBP-89 under various conditions, it is important to understand how each is regulated. While NF- $\mathrm{\kappa B}$ is the prototypical pro-inflammatory response factor, responsible for coordinating the induction of a variety of genes in response to pro-inflammatory cytokines, relatively little is known about regulation of ZBP-89. Here we show that ZBP-89 mRNA and protein levels are decreased by inflammatory cytokines IL- $1 \beta$ and TNF- $\alpha$ in human gingival fibroblasts isolated from patients with periodontitis, and by IL- $1 \beta$ and lipopolysaccharide (LPS) in WI-38 normal human diploid fibroblasts. Interestingly, TNF fails to inhibit ZBP-89 expression in WI-38 cells, suggesting some cell type specificity in the regulation of ZBP-89.

\section{Materials and methods}

\section{Cell culture}

Human gingival tissue from patients undergoing periodontal surgery was obtained from Newtown Dental Associates in Newtown, PA. The tissue was processed by enzymatic dispersion to produce primary fibroblast cultures (HGF). Cells were maintained in Eagle's minimal essential medium (EMEM) supplemented with 10\% fetal bovine serum and antibiotic/antimycotic (penicillin, streptomycin, amphotericin; Gibco BRL/Invitrogen, Carlsbad, CA, USA). Cells between passages 3 and 5 were used for experiments. WI-38 cells were obtained from ATCC (Manassas, VA, USA) and maintained as suggested.

\section{RNA isolation and real-time polymerase chain reaction}

Cells were serum-deprived for 16 hours in serum-free EMEM supplemented with 10\% ITS (insulin, transferrin, sodium selenite; Sigma-Aldrich, St. Louis, MO, USA) prior to the addition of the indicated doses of cytokines. IL-1 $\beta$ was obtained from DuPont-Merck Corp (Wilmington, DE, USA), IL-4 from Promega (Madison, WI, USA), and TNF $\alpha$ from Sigma-Aldrich. LPS was obtained from Calbiochem (San Diego, CA) and epidermal growth factor (EGF) from Biosource International, (Camarillo, CA, USA). Total RNA was isolated at the indicated times using the RNAqueous-4PCR kit (Ambion/Applied Biosystems,
Austin, TX, USA) according to manufacturer's instructions and reverse transcribed into cDNA using the High Capacity cDNA Archive Kit (Applied Biosystems) and Thermal Cycler Genius. Real-time polymerase chain reactions (PCR) consisted of $2 \mu \mathrm{l}$ of cDNA, $6.8 \mu \mathrm{l}$ of $\mathrm{H}_{2} \mathrm{O}, 10 \mu \mathrm{l}$ of the Premix Ex Taq ${ }^{\mathrm{TM}}$ (master mix and $0.4 \mu \mathrm{l}$ ROX Reference Dye; TAKARA, Madison, WI, USA) and $0.8 \mu$ probes (ZNF148, glyceraldehyde-3-phosphate dehydrogenase [GAPDH]; Applied Biosystems). Real-time PCR analysis was done using the Applied Biosystem 7500 Real Time PCR system. Reactions were done in triplicate and results were normalized to GAPDH.

\section{Protein isolation and Western blotting}

Whole cell extracts were prepared using the Nuclear Extraction Kit from Active Motif (Carlsbad, CA, USA) using the suggested procedure for whole cell extraction, and quantified in mini-Bradford assays (Pierce Biotech, Rockford, IL, USA). Thirty $\mu$ g extract were separated on 10\% SDS-polyacrylamide gels. Proteins were transferred to Immobilon-P Transfer Membrane (Millipore, Billerica, MA, USA) and the membrane was blocked overnight with Super Block blocking buffer (Pierce Biotech). The blot was then incubated with anti-ZBP-89 (Santa Cruz, Santa Cruz, CA, USA) antibody diluted 1:1000 in Super Block for one hour at room temperature. After washing three times in TBST (20 mM Tris- $\mathrm{HCl} \mathrm{pH} 7.5,150 \mathrm{mM} \mathrm{NaCl}, 0.5 \%$ Tween 20), the blots were incubated with a donkey anti-goat (for ZBP-89) secondary antibody conjugated to horseradish peroxidase (Pierce Biotech) for one hour. After three more washes in TBST, the blot was incubated with SuperSignal West Pico Chemiluminescent Substrate (Pierce Biotech) and exposed to X-ray film.

\section{Results}

Human gingival fibroblasts (HGF) were serum-deprived for 16 hours and then treated with IL-1 (10 ng/ml) and/or IL-4 $(10 \mathrm{ng} / \mathrm{ml})$ for 12 hours. ZBP-89 mRNA was measured by real-time PCR. Figure 1 shows a decrease in steady-state levels of ZBP-89 mRNA in response to the pro-inflammatory cytokine IL-1 $\beta$, but no change in response to the antiinflammatory IL-4. Tumor necrosis factor- $\alpha$ (TNF- $\alpha$ ) also inhibits ZBP-89 expression in HGF to a similar extent, and both inflammatory cytokines are effective at doses as low as $0.1 \mathrm{ng} / \mathrm{ml}$ (Figure 2). A time course shows that both mRNA and protein expression are inhibited within six hours of treatment with IL-1 $\beta$, and the levels continue to decrease for at least 24 hours (Figure 3 ). 


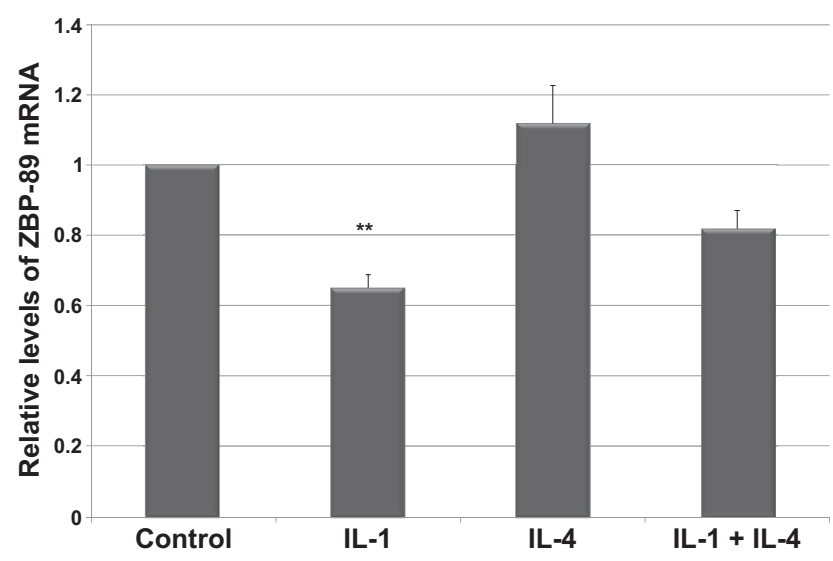

Figure I IL-I inhibits ZBP-89 mRNA expression in HGF. HGF cultures were serum-deprived for 16 hours prior to addition of IL-I $\beta(10 \mathrm{ng} / \mathrm{ml})$ and/or IL-4 $(10 \mathrm{ng} / \mathrm{ml})$. Total RNA was harvested 12 hours after cytokine treatment, quantitated by real-time PCR and normalized to levels of GAPDH.

Notes: The graph represents data from seven independent experiments performed in triplicate, expressed as mean \pm SEM. Statistical significance was determined using Student's $t$-test. **p $<0.01$.

Abbreviations: GAPDH, glyceraldehyde-3-phosphate dehydrogenase; HGF, human gingival fibroblasts; IL, interleukin; PCR, polymerase chain reaction; SEM, standard error of mean.

Since there have been some reports of altered responses in fibroblasts isolated from individuals with chronic inflammatory conditions, WI-38 normal human fibroblasts were used to compare responses. Our results (Figure 4) demonstrate a similar decrease in response to IL-1 $\beta$, no change in response to IL-4, transforming growth factor- $\beta$ (TGF- $\beta$ ), or EGF. LPS, however, did inhibit ZBP-89 expression, though not as much as IL-1 $\beta$. Interestingly, TNF did not inhibit ZBP-89 mRNA expression in these normal cells.

\section{Discussion}

Here we report that the expression of ZBP-89 is inhibited by inflammatory cytokines IL-1 $\beta$ and TNF- $\alpha$ in human gingival fibroblasts isolated from patients with severe periodontitis, and by IL- $1 \beta$ and LPS but not TNF- $\alpha$ in WI-38 normal human fibroblasts.

The mechanism of cytokine suppression of ZBP-89 mRNA levels was not determined. Since both mRNA and protein levels were significantly reduced within six hours, it is possible that there is a direct effect on transcription. However, changes in mRNA stability cannot be ruled out. Sequence analysis ${ }^{21}$ identified several putative transcription factor binding sites that were well conserved in the promoters of the mouse and human genes, including Sp1, TCF-1, Oct1, NF- $\kappa B$, MyoD, Ets1 LyF-1, and BERF-1/ZBP-89 itself, but a functional analysis of these elements has not been done. There was evidence of alternative polyadenylation sites in the $3^{\prime}$ untranslated region, ${ }^{21}$ but no AUUA elements associated with mRNA instability have been noted. In addition to regulation of the levels of ZBP-89 expressed,

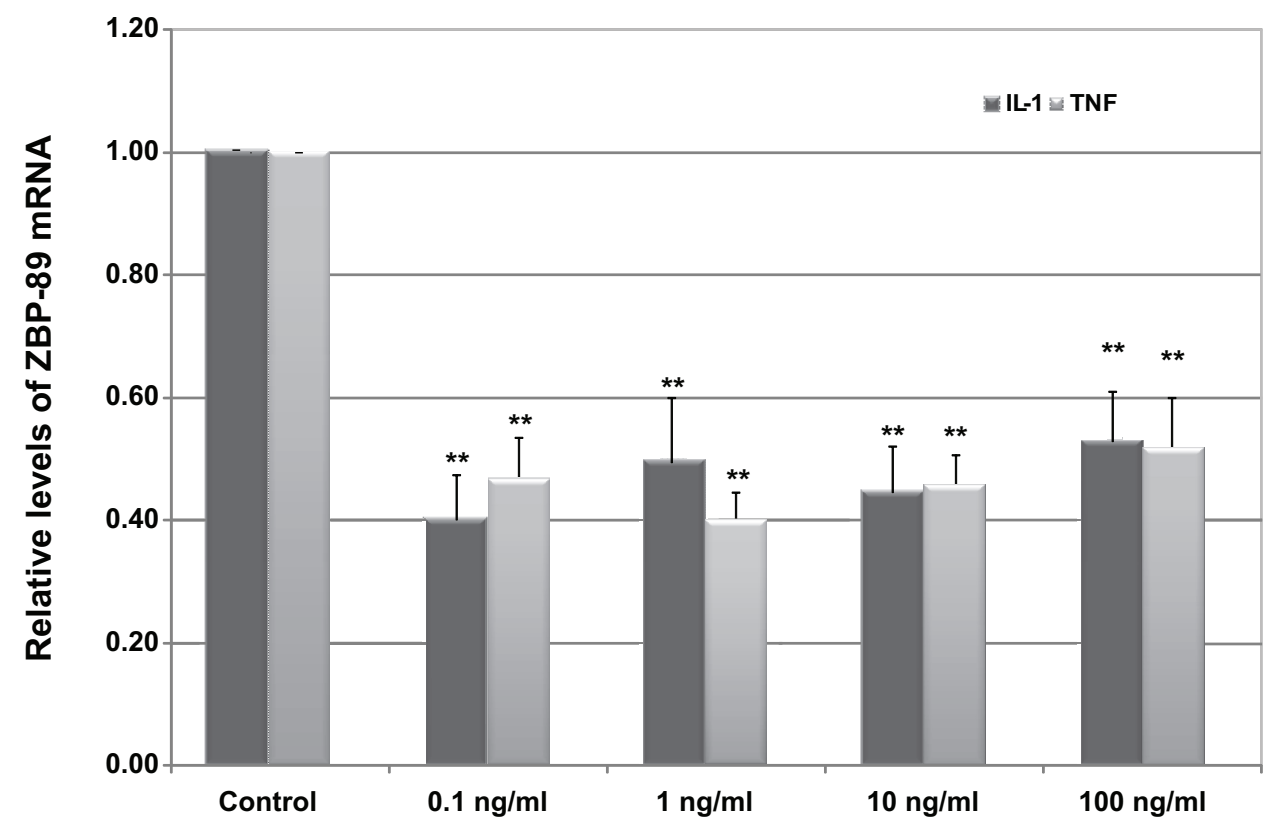

Figure 2 IL-I $\beta$ and TNF- $\alpha$ inhibit ZBP-89 mRNA expression at low doses. HGF cultures were serum-deprived for I6 hours prior to addition of IL-I $\beta$ (I0 ng/ml) or TNF- $\alpha$ $(10 \mathrm{ng} / \mathrm{ml})$. Total RNA was harvested 12 hours after cytokine treatment, quantitated by real-time PCR and normalized to levels of GAPDH.

Notes: The graph represents data from five independent experiments performed in triplicate, expressed as mean \pm SEM. Statistical significance was determined using Student's $t$-test. $* *$ p $<0.01$.

Abbreviations: GAPDH, glyceraldehyde-3-phosphate dehydrogenase; HGF, human gingival fibroblasts; IL, interleukin; PCR, polymerase chain reaction; SEM, standard error of mean; TNF, tumor necrosis factor. 
A

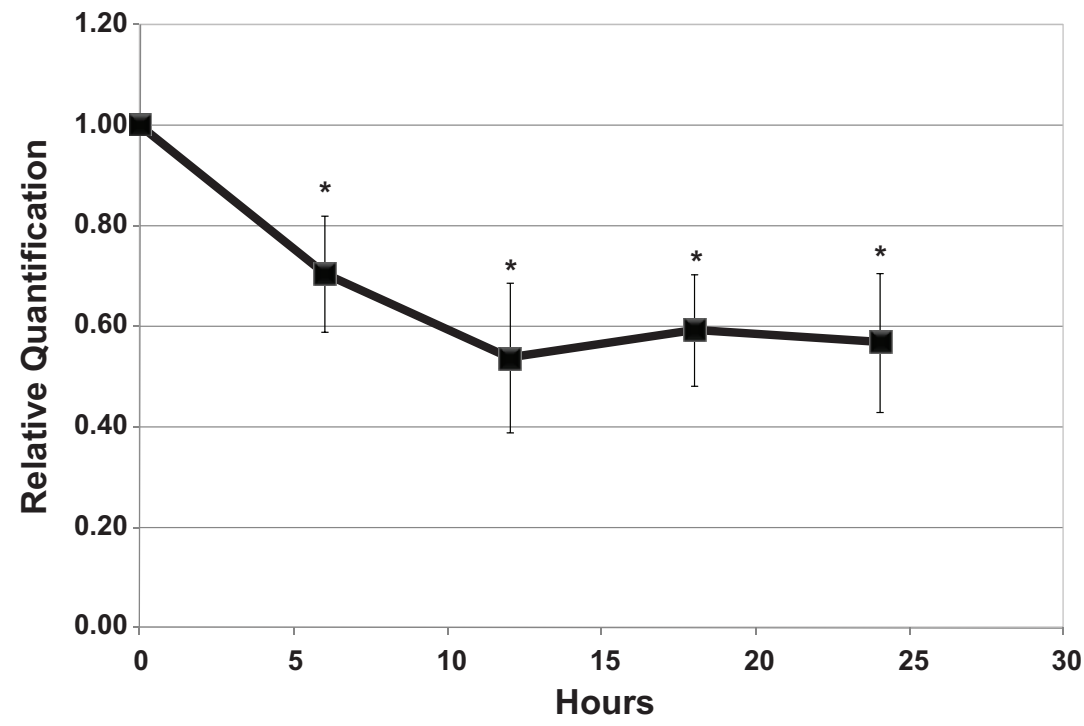

B

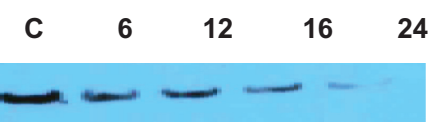

Figure 3 IL-I $\beta$ inhibits ZBP-89 mRNA expression within six hours. A) HGF cultures were serum-deprived for I6 hours prior to addition of IL-I $\beta$ (I0 ng/ml). Total RNA was harvested at the indicated hours after cytokine treatment, quantitated by real-time PCR and normalized to levels of GAPDH. B) Immunoblot of whole cell extracts isolated from HGF cultures treated for the indicated times with IL-I $\beta$ as described above and treated anti-ZBP-89 antibody.

Notes: The graph represents data from five independent experiments performed in triplicate, expressed as mean \pm SEM. Statistical significance was determined using Student's t-test. *p $<0.05$.

Abbreviations: GAPDH, glyceraldehyde-3-phosphate dehydrogenase; HGF, human gingival fibroblasts; IL, interleukin; PCR, polymerase chain reaction; SEM, standard error of mean.

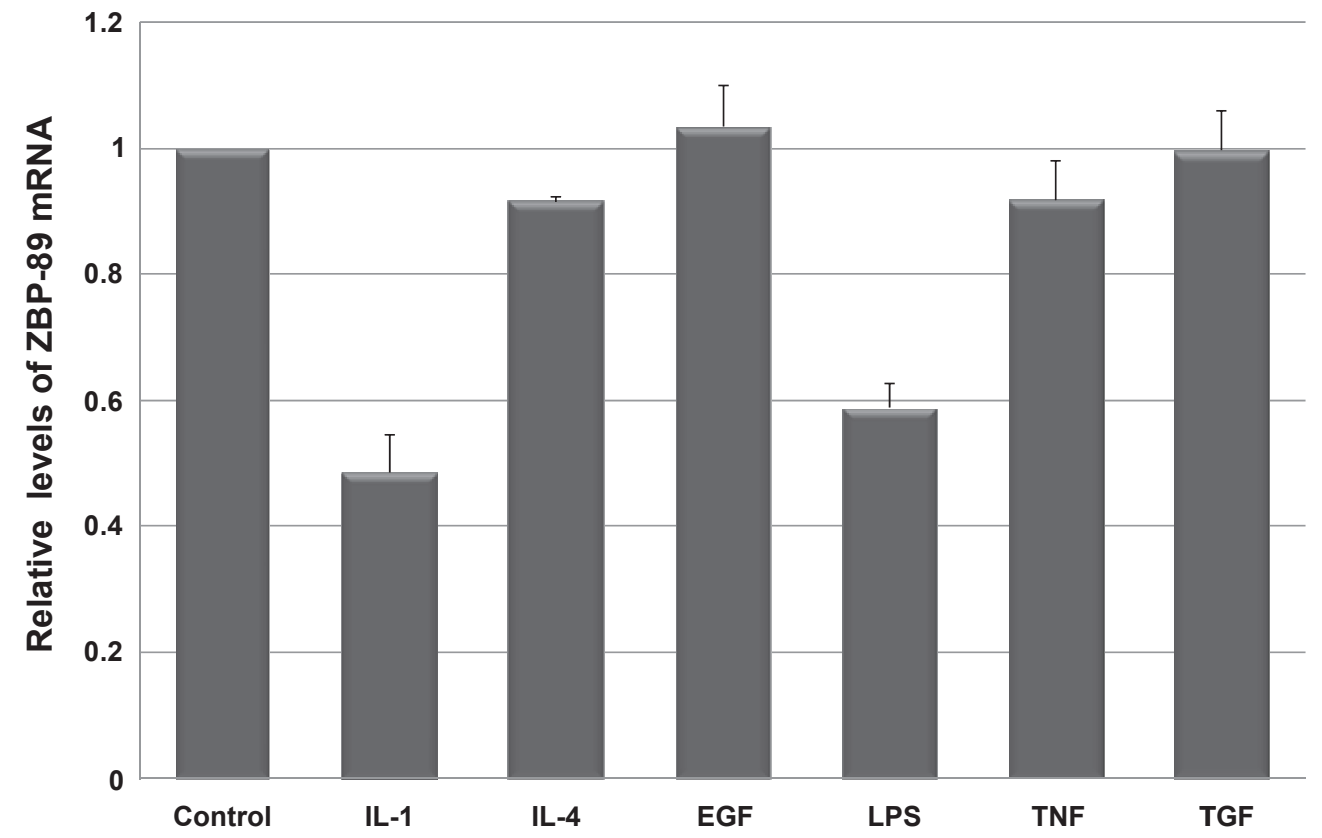

Figure 4 ZBP-89 mRNA is inhibited by IL-I $\beta$ and LPS, but not by TNF- $\alpha$ in WI-38 cells. WI-38 cell cultures were serum-deprived for I6 hours prior to addition of cytokines/ inflammatory mediator $(10 \mathrm{ng} / \mathrm{ml})$. Total RNA was harvested 12 hours after treatment, quantitated by real-time PCR, and normalized to levels of GAPDH.

Notes: The graph represents data from two independent experiments performed in triplicate, expressed as mean \pm SEM.

Abbreviations: GAPDH, glyceraldehyde-3-phosphate dehydrogenase; EGF, epidermal growth factor; IL, interleukin; LPS, lipopolysaccharide; PCR, polymerase chain reaction; TNF, tumor necrosis factor; SEM, standard error of mean. 
there is also evidence of post-translational regulation of ZBP-89 transcriptional activity by phosphorylation ${ }^{22}$ and/or sumoylation, ${ }^{23}$ but so far little is known about what kinds of stimuli might regulate these modifications, and in what cellular contexts.

Although ZBP-89 is ubiquitously expressed, it is more abundant in some tissues ${ }^{6,24,25}$ and there is evidence of developmental regulation of its expression. ${ }^{8}$ In addition, its mRNA has been shown to be modestly induced by retinoic acid ${ }^{26}$ as well as TGF- $\beta$ and butyrate. ${ }^{1,27}$ Although it has been shown to be over-expressed in certain cancers, ${ }^{28}$ it limits cell proliferation, in part through interactions with p53, ${ }^{29}$ and appears to have roles in cell differentiation ${ }^{8,30}$ and apoptosis. ${ }^{31}$ In addition, ZBP-89 has also been proposed to have a protective effect in the resolution of inflammation. ${ }^{32}$ Therefore, one might speculate that suppression of ZBP-89 expression by inflammatory cytokines might serve to allow cytokine mediated increases in cellular proliferation, prolong the immune response and/or protect against apoptosis. For example, both IL-1 and TNF have been shown to stimulate ornithine decarboxylase (ODC) expression, but only in cell types in which they are able to stimulate proliferation. ${ }^{33}$ It is tempting to speculate that they might do this, at least in part, by inhibiting ZBP-89 repression of ODC expression. On the MMP-3 promoter, decreased levels of ZBP-89 would presumably allow $\mathrm{NF}-\kappa \mathrm{B}$ to bind unopposed to both the $5 \mathrm{~T}$ and $6 \mathrm{~T}$ versions of the polymorphic site, causing both to function as repressor elements in vivo (although the 6T would be a more effective repressor element because of a higher affinity for $\mathrm{NF}-\kappa \mathrm{B}$ ). This would help to limit the amount of MMP-3 expressed, and thus reduce pathological tissue remodeling during prolonged inflammation.

It is interesting to note that although TNF- $\alpha$ inhibited ZBP-89 mRNA expression in HGF in a way similar to IL-1 $\beta$, it failed to do so in WI-38 cells. This suggests that there are cell-type specific differences in the TNF- $\alpha$ pathway as it relates to ZBP-89 expression. It is possible that these differences result from alterations in the HGF caused by chronic inflammation. For example, Rowanpura and colleagues $^{34}$ showed that HGF isolated from patients with severe periodontitis differed from normal gingival fibroblasts from healthy donors in their response to prostaglandin $\mathrm{E}_{2}$, and that this was a result of a change in receptors from $\mathrm{EP}_{2}$ and $\mathrm{EP}_{4}$ in healthy tissue to predominantly $\mathrm{EP}_{1}$ in diseased tissue. In another study, TNF- $\alpha$ induced proliferation of synovial fibroblasts isolated from patients with rheumatoid arthritis, but failed to do so in normal synovial fibroblasts. ${ }^{35}$

\section{Acknowledgments}

The authors would like to thank Bill Laidlaw for technical assistance and Kevan S Greene for providing gingival tissue samples. This work was funded by grant R15DE16277 from the NIH/NIDCR to RCB. The authors report no conflicts of interest in this work.

\section{References}

1. Bai L, Merchant JL. Transcription factor ZBP-89 cooperates with histone acetyltransferase p300 during butyrate activation of p21waf1 transcription in human cells. J Biol Chem. 2000;275(39): 30725-30733.

2. Bai L, Merchant JL. Transcription factor ZBP-89 is required for STAT1 constitutive expression. Nucleic Acids Res. 2003;31(24): 7264-7270.

3. Malo MS, Mozumder M, Zhang XB, et al. Intestinal alkaline phosphatase gene expression is activated by ZBP-89. Am J Physiol Gastrointest Liver Physiol. 2006;290(4):G737-G746.

4. Ye S, Whatling C, Watkins H, Henney A. Human stromelysin gene promoter activity is modulated by transcription factor ZBP-89. FEBS Lett. 1999;450(3):268-272.

5. Keates AC, Keates S, Kwon JH, et al. ZBP-89, Sp1, and nuclear factor-kappa B regulate epithelial neutrophil-activating peptide-78 gene expression in Caco-2 human colonic epithelial cells. J Biol Chem. 2001;276(47):43713-43722.

6. Law DJ, Tarle SA, Merchant JL. The human ZBP-89 homolog, located at chromosome $3 \mathrm{q} 21$, represses gastrin gene expression. Mamm Genome. 1998;9(2):165-167.

7. Merchant JL, Iyer GR, Taylor BR, et al. ZBP-89, a Kruppel-like zinc finger protein, inhibits epidermal growth factor induction of the gastrin promoter. Mol Cell Biol. 1996;16(12):6644-6653.

8. Passantino R, Antona V, Barbieri G, et al. Negative regulation of beta enolase gene transcription in embryonic muscle is dependent upon a zinc finger factor that binds to the G-rich box within the muscle-specific enhancer. J Biol Chem. 1998;273(1):484-494.

9. Petrovic I, Kovacevic-Grujicic N, Stevanovic M. ZBP-89 and Sp3 down-regulate while NF-Y up-regulates SOX18 promoter activity in HeLa cells. Mol Biol Rep. 2009;36(5):993-1000.

10. Zhang X, Diab IH, Zehner ZE. ZBP-89 represses vimentin gene transcription by interacting with the transcriptional activator, Sp1. Nucleic Acids Res. 2003;31(11):2900-2914.

11. Law GL, Itoh H, Law DJ, Mize GJ, Merchant JL, Morris DR. Transcription factor ZBP-89 regulates the activity of the ornithine decarboxylase promoter. J Biol Chem. 1998;273(32):19955-19964.

12. Borghaei RC, Gorski G, Javadi M. NF-kappaB and ZBP-89 regulate MMP-3 expression via a polymorphic site in the promoter. Biochem Biophys Res Commun. 2009;382(2):269-273.

13. Ye S, Eriksson P, Hamsten A, Kurkinen M, Humphries SE, Henney AM. Progression of coronary atherosclerosis is associated with a common genetic variant of the human stromelysin-1 promoter which results in reduced gene expression. J Biol Chem. 1996;271(22): 13055-13060.

14. Deguara J, Burnand KG, Berg J, et al. An increased frequency of the $5 \mathrm{~A}$ allele in the promoter region of the MMP3 gene is associated with abdominal aortic aneurysms. Hum Mol Genet. 2007;16(24): 3002-3007.

15. Medley TL, Kingwell BA, Gatzka CD, Pillay P, Cole TJ. Matrix metalloproteinase-3 genotype contributes to age-related aortic stiffening through modulation of gene and protein expression. Circ Res. 2003;92(11):1254-1261.

16. Abilleira $\mathrm{S}$, Bevan $\mathrm{S}$, Markus HS. The role of genetic variants of matrix metalloproteinases in coronary and carotid atherosclerosis. $J$ Med Genet. 2006;43(12):897-901. 
17. Astolfi CM, Shinohara AL, da Silva RA, Santos MC, Line SR, de Souza AP. Genetic polymorphisms in the MMP-1 and MMP-3 gene may contribute to chronic periodontitis in a Brazilian population. J Clin Periodontol. 2006;33(10):699-703.

18. White AJ, Duffy SJ, Walton AS, et al. Matrix metalloproteinase-3 and coronary remodelling: implications for unstable coronary disease. Cardiovasc Res. 2007;75(4):813-820.

19. Ye S, Watts GF, Mandalia S, Humphries SE, Henney AM. Preliminary report: genetic variation in the human stromelysin promoter is associated with progression of coronary atherosclerosis. Br Heart J. 1995; 73:209-215.

20. Holliday DL, Hughes S, Shaw JA, Walker RA, Jones JL. Intrinsic genetic characteristics determine tumor-modifying capacity of fibroblasts: matrix metalloproteinase-3 5A/5A genotype enhances breast cancer cell invasion. Breast Cancer Res. 2007;9(5):R67.

21. Feo S, Antona V, Cammarata G, et al. Conserved structure and promoter sequence similarity in the mouse and human genes encoding the zinc finger factor BERF-1/BFCOL1/ZBP-89. Biochem Biophys Res Commun. 2001;283(1):209-218.

22. Bai L, Merchant JL. ATM phosphorylates ZBP-89 at Ser202 to potentiate p21waf1 induction by butyrate. Biochem Biophys Res Commun. 2007;359(3):817-821.

23. Chupreta S, Brevig H, Bai L, Merchant JL, Iniguez-Lluhi JA. Sumoylation-dependent control of homotypic and heterotypic synergy by the Kruppel-type zinc finger protein ZBP-89. J Biol Chem. 2007;282(50):36155-36166.

24. Reizis B, Leder P. Expression of the mouse pre-T cell receptor alpha gene is controlled by an upstream region containing a transcriptional enhancer. J Exp Med. 1999;189(10):1669-1678.

25. Yamada A, Takaki S, Hayashi F, Georgopoulos K, Perlmutter RM, Takatsu K. Identification and characterization of a transcriptional regulator for the lck proximal promoter. J Biol Chem. 2001;276(21): 18082-18089.
26. Dawson MI, Park JH, Chen G, et al. Retinoic acid (RA) receptor transcriptional activation correlates with inhibition of 12-O-tetradecanoylphorbol-13-acetate-induced ornithine decarboxylase (ODC) activity by retinoids: a potential role for trans-RA-induced ZBP-89 in ODC inhibition. Int J Cancer. 2001;91(1):8-21.

27. Merchant JL, Bai L, Okada M. ZBP-89 mediates butyrate regulation of gene expression. J Nutr. 2003;133(7 Suppl):2456S-2460S.

28. Taniuchi T, Mortensen ER, Ferguson A, Greenson J, Merchant JL. Overexpression of ZBP-89, a zinc finger DNA binding protein, in gastric cancer. Biochem Biophys Res Commun. 1997;233(1): 154-160.

29. Bai L, Merchant JL. ZBP-89 promotes growth arrest through stabilization of p53. Mol Cell Biol. 2001;21(14):4670-4683.

30. Woo AJ, Moran TB, Schindler YL, et al. Identification of ZBP-89 as a novel GATA-1-associated transcription factor involved in megakaryocytic and erythroid development. Mol Cell Biol. 2008;28(8): 2675-2689.

31. Bai L, Yoon SO, King PD, Merchant JL. ZBP-89-induced apoptosis is p53-independent and requires JNK. Cell Death Differ. 2004;11(6): 663-673.

32. Park H, Shelley CS, Arnaout MA. The zinc finger transcription factor ZBP-89 is a repressor of the human beta 2-integrin CD11b gene. Blood. 2003;101(3):894-902.

33. Endo Y, Matsushima K, Onozaki K, Oppenheim JJ. Role of ornithine decarboxylase in the regulation of cell growth by IL-1 and tumor necrosis factor. J Immunol. 1988;141(7):2342-2348.

34. Ruwanpura SM, Noguchi K, Ishikawa I. Prostaglandin E2 regulates interleukin-1beta-induced matrix metalloproteinase-3 production in human gingival fibroblasts. J Dent Res. 2004;83(3):260-265.

35. Youn J, Kim HY, Park JH, et al. Regulation of TNF-alpha-mediated hyperplasia through TNF receptors, TRAFs, and NF-kappaB in synoviocytes obtained from patients with rheumatoid arthritis. Immunol Lett. 2002;83(2):85-93.
Pathology and Laboratory Medicine International

\section{Publish your work in this journal}

Pathology and Laboratory Medicine International is a peer-reviewed, open access journal focusing on innovative basic research and translational research related to pathology or human disease. The journal includes original research, updates, case reports, reviews and commentaries on current controversies. The Academic Sponsor

\section{Dovepress}

of this journal is the Chinese American Pathology Association (CAPA). The manuscript management system is completely online and includes a very quick and fair peer-review system. Visit http://www.dovepress.com/testimonials.php to read real quotes from published authors. 